\title{
Períodos de convivência entre o trigo e plantas daninhas combinados a
} regulador de crescimento ${ }^{1}$

\section{Coexistence periods between wheat crop and weeds combined with growth} regulator

\author{
Samantha Cenci ${ }^{2}$; Jeferson Zagonel ${ }^{3}$; Camila Ferreira ${ }^{4}$; Marina Senger ${ }^{5}$
}

Resumo - O uso de regulador de crescimento na cultura do trigo é uma prática usual, sendo um dos seus efeitos a mudança de arquitetura das plantas, a qual pode interferir na época de início de controle das plantas daninhas. Visando avaliar a influência do efeito do regulador de crescimento (trinexapac-ethyl) nas características agronômicas e na produtividade do trigo, determinando assim a melhor época para o início do controle das plantas daninhas na cultura, um experimento foi instalado em Ponta Grossa/PR, no ano de 2011. O delineamento experimental utilizado foi o de blocos ao acaso, em esquema fatorial 2 x 10, representados pelo uso ou não de regulador de crescimento e 10 períodos de convivência entre plantas daninhas e a cultivar de trigo Quartzo. A época ideal de início de controle das plantas daninhas, de forma a não ocorrer redução de produtividade, foi de até 25 dias após a emergência (DAE), independente do uso ou não do trinexapac-ethyl como regulador de crescimento, o qual reduziu a altura de plantas, o comprimento das folhas e o índice de área foliar, porém sem interferir na produtividade e na época de controle das plantas daninhas.

Palavras-chaves: plantio direto, Triticum aestivum, produtividade, trinexapac-ethyl

Abstract - The use of growth regulators in wheat crop is a usual practice, and one of its effects is the changing in plants architecture, what may interfere in the early season for weeds control. With the objective of evaluating the influence of growth regulator (trinexapac-ethyl) effect over agronomic characteristics and wheat yield, in order to determining the best period to initiating weeds control in wheat crop, an experiment was conducted in Ponta Grossa County, Parana State in 2011 agricultural year. Experimental design used was randomized complete blocks, in factorial scheme $2 \times 10$, represented by two treatments with or without growth regulators and 10 coexistence periods between weeds and wheat crop Quartzo genotype. The ideal period for initiating weeds control, avoiding yield reduce was up to 25 days after emergence (DAE), independent or no of trinexapac-ethyl use as growth regulator, that decreased plant height, leaves length and leaf area index, but without interfering over yield and weeds control period.

Keywords: no tillage, Triticum aestivum, yield, trinexapac-ethyl

\footnotetext{
${ }^{1}$ Recebido para publicação em 18/09/2013 e aceito em 03/02/2014.

${ }^{2}$ Mestranda do Programa de Pós-Graduação em Agronomia da Universidade Estadual de Ponta Grossa (UEPG), Av. General Carlos Cavalcanti, 4748, 84030-900, Ponta Grossa, PR. Email: <sah_cenci@hotmail.com). (Autora para correspondência).

${ }^{3}$ Professor do Departamento de Fitotecnia e Fitossanidade da Universidade Estadual de Ponta Grossa (UEPG).

${ }^{4}$ Doutoranda do Programa de Pós-Graduação em Agronomia da Universidade Estadual de Ponta Grossa (UEPG).

${ }^{5}$ Doutoranda do Programa de Pós-Graduação em Agronomia da Universidade Estadual de Ponta Grossa (UEPG).
} 


\section{Introdução}

A maior parte do trigo (Triticum aestivum) consumido no Brasil é importada. No entanto, a cultura é o principal cultivo econômico no inverno em alguns estados do País, como o Paraná, onde o produtor tem condições de produzir trigo de excelente qualidade utilizando as tecnologias disponíveis. Um dos pontos-chave para atingir esse objetivo é o manejo adequado das plantas daninhas (Penckowski et al., 2003).

Quanto maior a população da comunidade infestante que ocorre no trigo, maior será a quantidade de indivíduos que disputam os recursos do meio como nutrientes minerais, luz, água e o espaço (Pitelli, 1985), mais intensa será a competição com a cultura. Além disso, espécies morfológica e fisiologicamente próximas apresentam exigências semelhantes em relação aos recursos do meio, tornando ainda mais intensa a competição (Silva \& Durigan, 2006). Altura elevada, alto índice de área foliar, elevada interceptação da radiação fotossinteticamente ativa e produção de matéria seca são características morfológicas desejáveis para uma cultivar visando a superioridade da cultura na matocompetição (Fleck et al., 2006; Rigoli et al., 2008; 2009).

Desta maneira, determinar o período de controle das plantas daninhas é imprescindível para obter sucesso na produtividade e também para a escolha do método de controle ideal, pois o grau de competição entre plantas daninhas e a cultura pode ser alterado em função do período em que a comunidade estiver disputando determinado recurso (Brighenti et al., 2004). No manejo do trigo, as plantas daninhas devem ser controladas no início do desenvolvimento da cultura, devendo esse ser eficiente e realizado na época ideal para que não ocorram perdas por matocompetição. No entanto essa época não é bem definida (Zagonel, 2005).

Outra estratégia de manejo que visa o aumento da produtividade do trigo é o uso de reguladores de crescimento, uma vez que técnicas de manejo como o uso de doses elevadas de nitrogênio aumenta o número de espigas por área, a produtividade e a altura de plantas, mas pode causar o acamamento das mesmas, interferindo negativamente na produtividade (Zagonel \& Fernandes, 2007). Assim, ainda são necessárias pesquisas sobre a possível influência que pode ocorrer no manejo das plantas daninhas devido à aplicação de reguladores de crescimento.

Reguladores de crescimento que atuam como inibidores de giberelinas (GA) são usados comercialmente para evitar o alongamento de colmos em algumas culturas. Para a cultura do trigo, o trinexapac-ethyl têm apresentado bons resultados na redução da altura das plantas e de perdas por acamamento (Zagonel \& Fernandes, 2007; Espindula et al., 2009; Espindula et al., 2010). Zagonel \& Fernandes (2007) constataram que o trinexapac-ethyl além da reduzir o acamamento, também promoveu aumento de produtividade, causado pela melhor distribuição dos fotoassimilados para os grãos, já que a área foliar e altura de plantas diminuíram acentuadamente, alterando a arquitetura da planta. No entanto, essa diminuição de altura de plantas pode afetar o controle cultural do trigo em relação às plantas daninhas, e assim as épocas de controle podem variar pelo uso ou não do trinexapac-ethyl e/ou outro regulador de crescimento.

Nesse sentido, um experimento foi realizado visando avaliar a influência do efeito do regulador de crescimento trinexapac-ethyl nas características agronômicas e na produtividade da cultura do trigo, assim como da melhor época de início do controle das plantas daninhas.

\section{Material e Métodos}

$\mathrm{O}$ experimento foi instalado no ano de 2011, no município de Ponta Grossa, PR. O solo do local é classificado como Cambissolo distrófico TB de textura argilosa (Embrapa, 
2006). A análise granulométrica apresentou $460 \mathrm{~g} \mathrm{~kg}^{-1}$ de argila, $179 \mathrm{~g} \mathrm{~kg}^{-1}$ de silte e $361 \mathrm{~g}$ $\mathrm{kg}^{-1}$ de areia. Os dados das propriedades químicas do solo encontram-se dispostos na Tabela 1.

Tabela 1. Características químicas do solo da área experimental (talhão A1G). Ponta Grossa/PR, 2011.

\begin{tabular}{|c|c|c|c|c|c|c|c|c|c|c|}
\hline \multirow{2}{*}{$\begin{array}{l}\text { Profundidade } \\
(\mathrm{cm})\end{array}$} & $\mathrm{pH}$ & $\mathrm{H}+\mathrm{Al}$ & $\mathrm{Ca}$ & $\mathrm{Mg}$ & $\mathrm{K}$ & CTC & $\mathrm{V}$ & $\mathrm{M}$ & $\mathrm{P}$ & $\mathrm{C}$ \\
\hline & \multicolumn{5}{|c|}{$\mathrm{cmol}_{\mathrm{c}} \cdot \mathrm{dm}^{-3}$} & $(\mathrm{pH} 7,0)$ & $\%$ & $\%$ & mg.dm ${ }^{-3}$ & g. $\mathrm{dm}^{-3}$ \\
\hline $0-10$ & 5,6 & 4,96 & $\overline{6,4}$ & $\overline{2}$ & 1 & 13,89 & 64,3 & 0 & 34,4 & 33 \\
\hline $10-20$ & 5,6 & 4,96 & 4,2 & 1,9 & 0 & 11,46 & 56,7 & 0 & 7,1 & 23 \\
\hline
\end{tabular}

O delineamento experimental utilizado foi o de blocos ao acaso, com quatro repetições, em esquema fatorial $2 \times 10$, sendo dois os tratamentos com ou sem regulador de crescimento e dez os períodos de convivência entre plantas daninhas e a cultivar de trigo Quartzo. Os tratamentos constaram de 10 épocas de convivência das plantas daninhas com o trigo, conforme descrito na Tabela 2 , determinadas pelo controle químico a cada sete dias a partir da emergência do trigo (18/07/2011) e da aplicação ou não do regulador de crescimento trinexapac-ethyl, na dose de $125 \mathrm{~g} \mathrm{ha}^{-1}$. A aplicação do regulador de crescimento foi realizada quando o trigo encontrava-se com um a dois nós perceptíveis, caracterizado entre os estádios 31 e 32 da escala de Zadoks et al. (1974).

Tabela 2. Épocas de controle das plantas daninhas e seus respectivos estádios fisiológicos. Ponta Grossa/PR, 2011.

\begin{tabular}{cccc}
\hline Épocas & Data & DAE & Estádios de desenvolvimento \\
\hline 1 & $18 / 7$ & 0 & Emergência da plântula \\
2 & $25 / 7$ & 7 & 6 folhas desenvolvidas \\
3 & $1 / 8$ & 14 & Perfilhamento \\
4 & $8 / 8$ & 21 & Elongação do colmo \\
5 & $15 / 8$ & 28 & Surgimento da folha bandeira \\
6 & $22 / 8$ & 35 & Folha bandeira expandida \\
7 & $29 / 8$ & 42 & Inicio do florescimento \\
8 & $5 / 9$ & 49 & 3/4 do florescimento completo \\
9 & $12 / 9$ & 56 & Antese \\
10 & $19 / 9$ & 63 & Desenvolvimento do grão \\
\hline
\end{tabular}

O sistema de cultivo adotado foi o plantio direto na palha, sendo a cultura antecessora o milho. O trigo, cultivar Quartzo, foi semeado em fileiras espaçadas em $0,17 \mathrm{~m} \mathrm{e}$ densidade de semeadura de 60 a 70 sementes por metro de fileira. As parcelas foram compostas de 18 fileiras de trigo com $6 \mathrm{~m}$ de comprimento. Foi considerada como área útil 12 fileiras centrais com $5 \mathrm{~m}$ de comprimento. A semeadura foi realizada no dia 06/07/11, utilizando como tratamento de sementes 25,11 $\mathrm{g}$ de triadimenol e $35,0 \mathrm{~g}$ de thiamethoxam por $100 \mathrm{~kg}$ de sementes, e adubação de $350 \mathrm{~kg} \mathrm{ha}^{-1}$ de adubo de fórmula 05-25-25 (NPK) no sulco de semeadura, assim como $90 \mathrm{~kg} \mathrm{ha}^{-1}$ de nitrogênio em cobertura.

O herbicida utilizado para o controle das plantas daninhas foi $o$ iodosulfuron metílico, aplicado na dose de $100 \mathrm{~g} \mathrm{ha}^{-1}$. Para a pulverização do iodosulfuron metílico e do trinexapac-ethyl foi utilizado um pulverizador costal pressurizado a $\mathrm{CO}_{2}$, em pressão 
constante de 206,85 $\mathrm{kPa}$, equipado com cinco pontas de jato plano tipo leque XR 110-02, e volume de calda equivalente a $200 \mathrm{~L} \mathrm{ha}^{-1}$. Conforme a aplicação na época determinada, as parcelas foram mantidas limpas até a colheita. Para isso foi utilizado $70 \mathrm{~g} \mathrm{ha}^{-1}$ de iodosulfurom- metílico para manutenção da área livre das plantas daninhas, a qual foi realizada sempre que a reinfestação de plantas daninhas era significativa.

O controle de doenças e de pragas foi realizado de acordo com a recomendação oficial para o trigo, no estado do Paraná, no ano de 2011 e constaram de duas aplicações de trifloxistrobina + tebuconazol para o controle de doenças e de lambda-cialotrina + tiametoxam para o controle de pragas, ambas nas doses recomendadas pelo fabricante.

$\mathrm{Na}$ fase de florescimento do trigo foram avaliadas as características agronômicas, coletando-se aleatoriamente 10 plantas por parcela. Avaliou-se o número de perfilhos, a altura de plantas, a qual foi determinada medindo-se cada planta da base do solo até a espiga; o diâmetro de caule, utilizando um paquímetro digital; a área foliar, através do aparelho digital integrador óptico de área; o comprimento e largura das folhas bandeira e bandeira -1 .

$\mathrm{Na}$ época da colheita foi determinada a produtividade por meio da massa total de grãos da área útil de cada parcela, corrigindo a umidade para $13 \%$.

Os dados obtidos foram submetidos à análise de variância, pelo teste de F. As diferenças entre as médias do uso ou não do trinexapac-ethyl, quando significativas, foram submetidas ao teste de Tukey a $5 \%$ de probabilidade. As épocas de controle foram analisadas por regressão polinomial, sendo utilizada a DMS Tukey $(\mathrm{p}<0,05)$ para definição do limite de convivência.

\section{Resultados e Discussão}

Não ocorreram interações significativas entre as épocas de controle das plantas daninhas e do uso ou não do trinexapac-ethyl para todas as varáveis analisadas.

A folha bandeira é considerada a fonte primária para o enchimento de grãos, devido à curta distância da espiga e ao fato de ela se manter verde por mais tempo do que as demais folhas da planta e é responsável pela maior parte da produção (Domiciano et al., 2009). Portanto, observou-se que o comprimento da folha bandeira, assim como do índice de área foliar e altura das plantas, foram menores com a aplicação de trinexapac-ethyl (Tabela 3), com redução proporcional a ocorrida para a altura das plantas. Segundo Fernandes (2009), tanto o comprimento como a largura da folha bandeira são características de cada cultivar, as quais podem ser alteradas com o uso do trinexapacethyl., o que influencia indiretamente o índice de área foliar das plantas de trigo, pelos efeitos no número, comprimento e largura das folhas. Tanto o comprimento de folha bandeira quanto o índice de área foliar diminuíram pelo uso do trinexapac-ethyl, o que corroborando com os resultados do referido autor.

Nesse sentido, o equilíbrio entre os níveis endógenos de auxinas e giberelinas é de grande importância para o alongamento celular, pois atuam de maneira conjunta no aumento da extensibilidade da parede celular, bem como na síntese de ativação de enzimas que atuam na reconstrução da parede celular (Taiz \& Zeiger, 2009). No trabalho, a inibição da biossíntese de giberelinas provocada pela aplicação do regulador de crescimento causou redução do comprimento das folhas, resultando em diminuição do índice de área foliar.

A redução da altura de plantas de trigo com a aplicação do trinexapac-ethyl (Tabela 3) é um resultado similar ao observado por diversos autores, (Fioreze \& Rodrigues, 2012; Zagonel \& Fernandes, 2007), sendo esse efeito explicado pela inibição da biossíntese de giberelinas provocada pelo regulador de crescimento. Outros autores pesquisaram a aplicação do trinexapac-ethyl em outras culturas, como milho, porém não observaram 
redução na altura das plantas como ocorreu no presente trabalho para o trigo (Zagonel \& Ferreira, 2013).

Não foram observadas diferenças significativas de produtividade com o uso de trinexapac-ethyl (Tabela 3). Lima \& Lovato (1995) verificaram que a não resposta da produtividade à aplicação de reguladores de crescimento pode estar relacionada à ausência de acamamento, devido a condições climáticas e a fertilidade do solo. Já Zagonel \& Fernandes (2007) constataram que, independentemente da ocorrência ou não de acamamento, o uso de trinexapac-ethyl promove o aumento da produtividade em trigo, devido a uma melhor distribuição dos fotoassimilados para os grãos, já que a altura e a massa de plantas diminuem.

Tabela 3. Comprimento da folha bandeira (CB), índice de área foliar (IAF), altura de plantas (AP) e produtividade (PROD) do trigo, cultivar Quartzo, em função de com ou sem a aplicação trinexapac-ethyl. Ponta Grossa/PR, 2011.

\begin{tabular}{ccccc}
\hline Trinexapac-ethyl & CB $(\mathrm{m})$ & IAF & AP $(\mathrm{m})$ & PROD $\left({\left.\mathrm{kg} \cdot \mathrm{ha}^{-1}\right)}^{-1}\right.$ \\
\hline Com & $0,18 \mathrm{~b}$ & $9,1 \mathrm{~b}$ & $0,79 \mathrm{~b}$ & $2176 \mathrm{a}$ \\
Sem & $0,21 \mathrm{a}$ & $13,6 \mathrm{a}$ & $0,98 \mathrm{a}$ & $2121 \mathrm{a}$ \\
\hline F $^{*}$ & 52,66 & 6,12 & 206,64 & 0,35 \\
D.M.S & 0,08 & 3,50 & 0,02 & 183,60 \\
C.V $(\%)$ & 8,8 & 48,0 & 6,5 & 19,1 \\
\hline
\end{tabular}

- Médias na mesma coluna seguidas da mesma letra não diferem entre si, a 5\% de probabilidade pelo teste de Tukey. $* \mathrm{p} \leq 0,05$.

A infestação de plantas daninhas foi $\mathrm{m}^{-2}$ de Avena strigosa e 11 plantas $\mathrm{m}^{-2}$ de avaliada um dia antes da aplicação do regulador de crescimento, havendo 13 plantas $\mathrm{m}^{-2}$ de Raphanus raphanistrum, de 17 plantas

\section{outras espécies.}

A produtividade da cultura do trigo diminuiu com o atraso do início de controle de plantas daninhas (Figura 1).

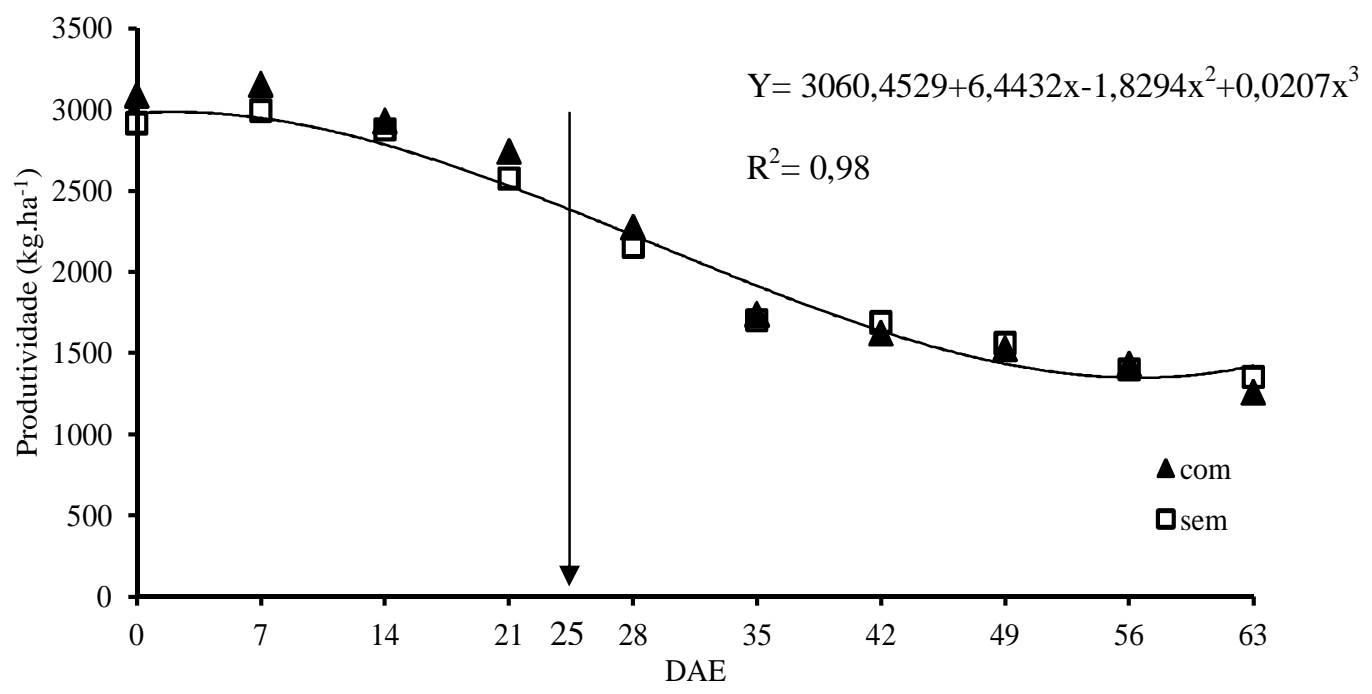

Figura 1. Produtividade das plantas de trigo cultivar Quartzo, em função da época de convivência de plantas daninhas. Ponta Grossa, 2011. 
A competição foi mais acentuada a partir de 25 dias após a emergência (DAE), quando o trigo estava no estádio 31 da escala de Zadoks et al. (1974). Resultado similar foi encontrado por Zagonel (2005), o qual constatou que o controle deve ser realizado até o final do perfilhamento, já que a redução mais elevada na produtividade ocorre quando a competição se dá na fase inicial de desenvolvimento da cultura. Agostinetto et al. (2008) mencionaram que medidas de controle de plantas daninhas na cultura do trigo devem ser adotadas no período entre 12 e 24 DAE. Já Zagonel \& Fernandes (2010) relatam que para não haver redução da produtividade da cultura do trigo, a controle das plantas daninhas deve ser realizado até 32 DAE. Esses resultados e os encontrados no presente trabalho demonstram as vantagens do controle das plantas daninhas na fase inicial de desenvolvimento da cultura, especialmente até a fase de perfilhamento.

\section{Conclusões}

O regulador de crescimento trinexapacethyl reduziu a altura de plantas, o comprimento das folhas, mas não afetou a produtividade e a época de início de controle de plantas daninhas.

A época ideal de início de controle das plantas daninhas foi de até 25 DAE, sem causar perdas na produtividade, independente ou não do uso de trinexapac-ethyl.

\section{Referências}

AGOSTINETTO, D. et al. Período crítico de competição de plantas daninhas com a cultura do trigo. Planta Daninha, v.26, n.2, p.271278, 2008.

BRIGHENTI, A.M. et al. Períodos de interferência de plantas daninhas na cultura do girassol. Planta Daninha, v.22, n.2, p.251257, 2004.

DOMICIANO, G.P. et al. Alterações na fotossíntese de plantas infectadas por fitopatógenos. Revisão Anual de Patologia de Plantas, v.17, n.1, p.305-339, 2009.

EMPRESA BRASILEIRA DE PESQUISA AGROPECUÁRIA - EMBRAPA. Métodos de controle de plantas daninhas em trigo, 2006. Disponível em: <http://www.cnpt.embrapa.br/biblio/do/p_do63 _3.htm>. Acesso em: 02 de abril 2013.

ESPINDULA, M.C. et al. Efeitos de reguladores de crescimento na elongação do colmo de trigo. Acta Scientiarum Agronomy, v.32, n.1, p.109-116, 2010.

ESPINDULA, M.C. et al. Use of growth retardants in wheat. Planta Daninha, v.27, n.2, p.379-387, 2009.

FERNANDES, E.C. População de plantas e regulador de crescimento afetando a produtividade de cultivares de trigo. 2009. 99f. Dissertação (Mestrado em Agronomia) Universidade Estadual de Ponta Grossa, Ponta Grossa, 2009.

FIOREZE, S.L.; RODRIGUES, J.D. Efeito da densidade de semeadura e de reguladores vegetais sobre os caracteres mofofisiológicos da folha bandeira do trigo. Revista Brasileira de Ciências Agrárias, v.7, n.1, p.89-96, 2012.

FLECK, N.G. et al. Interferência de Raphanus sativus sobre cultivares de soja durante a fase vegetativa de desenvolvimento da cultura. Planta Daninha, v.24, n.3, p.425-434, 2006.

LIMA, M.R.S.; LOVATO, C. Efeito do Chlormequat sobre quatro cultivares de trigo em duas épocas de semeadura. Revista Científica do Centro de Ciências Rurais, v. 25, n.3 p.371-374, 1995.

PENCKOWSKI, L.H. et al. Influência das condições climáticas no momento da aplicação de herbicidas pós-emergentes sobre a eficácia de controle de nabiça (Raphanus raphanistrum) na cultura de trigo. Planta Daninha, v.21, n.3, p.435-442, 2003. 
PITELLI, R.A. Interferências de plantas daninhas em culturas agrícolas. Informe Agropecuário, v.11, n.129, p.16-27, 1985.

RIGOLI, R.P. et al. Habilidade competitiva relativa do trigo (Triticum aestivum) em convivência com azevém (Lolium multiflorum) ou nabo (Raphanus raphanistrus). Planta Daninha, v.26, n.1, p.93-100, 2008.

RIGOLI, R.P. et al. Potencial competitivo de cultivares de trigo em função do tempo de emergência. Planta Daninha, v.27, n.1, p.4147, 2009.

SILVA, M.R.M.; DURIGAN, J.C. Períodos de interferência das plantas daninhas na cultura do arroz de terras altas. I - Cultivar IAC 202. Planta Daninha, v.24, n.4, p.685-694, 2006.

TAIZ, L.; ZEIGER, E. Fisiologia vegetal. 4.ed. Porto Alegre: Artmed, 2009.

ZADOKS, J.C. et al. A decimal code for the growth stages of cereals. Weed Research, v.14, n.6, p.415-421, 1974.

ZAGONEL, J. Eficácia do herbicida Hussar (iodosulfuron methylsodium) no controle de plantas daninhas na cultura do trigo. In: REUNIÃO DA COMISSÃO CENTRO-SUL BRASILEIRA DE PESQUISA DE TRIGO E TRITICALE, 20. Resumos... Londrina, PR. Embrapa Soja/Iapar: Londrina, PR, p.1-3, 2005.

ZAGONEL, J.; FERNANDES, E.C. Doses e épocas de aplicação de redutor de crescimento afetando cultivares de trigo em duas doses de nitrogênio. Planta Daninha, v.25, n.2, p.331339, 2007.

ZAGONEL, J.; FERNANDES, E.C. Plantas daninhas em trigo - quando controlar. Cultivar Grandes Culturas, v.12, n.1, p.26-28, 2010.

ZAGONEL, J.; FERREIRA, C. Doses e épocas de aplicação de regulador de crescimento em híbridos de milho. Planta Daninha, v.31, n.2, p.395-402, 2013. 